\title{
The Energy Saving Effect of Different Wall Insulation Configurations with the Intermittent and Compartmental Heating Method
}

\author{
Fang Ruan, Xiaoqian Qian, and Kuangliang Qian
}

\begin{abstract}
In hot summer and cold winter zone of China, the intermittent and compartmental heating method of air conditioning is widely adopted. The intermittent heating method makes the heat storage in walls become the main way for heat dissipation. The compartmental heating method results in a large amount of heat loss not only in exterior walls, but also in interior walls. Based on this heating method, a series of experiments were conducted in Shaoxing, a typical city in the hot summer and cold winter zone. The results showed that, internal insulating method for exterior wall could save more energy than external insulating method by reducing the wall heat storage amount. Besides, both the exterior walls and interior walls should be insulated as the heat loss in interior walls accounts for a large proportion of the total heating load and whether the adjacent room heating or not has little effect on reducing it.
\end{abstract}

Index Terms-Building energy efficiency, compartmental heating, intermittent heating, residential building, thermal insulation, thermal storage.

\section{INTRODUCTION}

Building energy efficiency is an important national strategy for China and insulation for building envelope is one of the most effective ways to achieve building energy efficiency [1]-[6]. During the last two decades, a substantial amount of research work has been carried out in the area of the dynamic thermal characteristic of wall and its influence on building energy consumption. Previous extensive research was mostly based on the method of continuous energy consuming in the whole building. In the hot summer and cold winter zone of China, there widely exists the intermittent and compartmental characteristic in residential building when heating in winter. The intermittent heating method makes the heat storage in walls become the main way for heat dissipation. The compartmental heating method results in a large amount of heat loss not only in exterior walls, but also in interior walls. With this heating method, the energy saving effect of different wall insulation configurations are still unclear currently. The energy saving measures in this region, to a large extent, are copied from the northern cold area where buildings served by air conditioner with full time in the whole space and widely adopt exterior wall external

Manuscript received December 18, 2015; revised May 2, 2016. This work was supported in part by the National Science $\&$ Technology Pillar Program during the 12th Five-year Plan Period under Grant 2012BAJ12B02.

The authors are with the College of Civil Engineering and Architecture, Zhejiang University, Hangzhou 310058, China (e-mail: ruanfang@zju.edu.cn, qianxq1@zju.edu.cn, qklcivil@zju.edu.cn). insulation system. However, the energy saving rate was far below expectation after the system being generalized in the hot summer and cold winter zone [7].

The influences on air conditioning (A/C) load of continuous and intermittent heating methods are different with each other. Exterior wall external insulation can significantly reduce A/C load with continuous heating method [8], [9]. The intermittent heating method results in the wall continuous exchanging heat with outdoor environment. As the amount of heat storage in building envelope is much larger than that of air, the energy saving effect of internal insulation will be better than external insulation with this heating method [10]. There were some researches also showed that with the intermittent cooling method, exterior wall external insulation may increase building cooling load. Pan group [11] studied the energy saving effect of exterior wall external insulation in three different climate regions (Beijing, Shanghai and Guangzhou) of China. Results showed that the energy saving effect of exterior insulation was the best in Beijing where heating load was the main part of annual A/C load. While in Guangzhou, there was obvious anti-insulation behavior for exterior insulation. In Shanghai, the critical thickness of exterior insulation for energy saving was $26 \mathrm{~mm}$. The explanation can be summarized as follows. After heated by the solar radiation in the daytime, the wall reached a relatively high temperature in summer. When intermittent cooling in the night, the wall temperature will higher than the indoor and outdoor air. Under this condition, if exterior walls were external insulated, the heat dissipating to indoor side would be much more than outdoor side and the $\mathrm{A} / \mathrm{C}$ cooling load would be raised. Specific experiments are still lacking to validate this conclusion.

When $\mathrm{A} / \mathrm{C}$ system was operating in the whole building, the temperature of each room was basically identical with each other and the heat transfer through partitions was small. While with the compartmental energy consuming method, a large amount of heat transfer would not only exists in exterior walls, but also exists in interior walls. In extreme operation case, the heat loss through partitions accounts for about $70 \%$ of the total energy consumption [12]. Therefore, with the compartmental energy consuming method, the effect on reducing the total energy consumption would not obvious if partitions were uninsulated. Moreover, the most economical insulation layer thickness on partitions needs economic analysis and engineering practice to verify.

Due to the intermittent and compartmental heating method for residential buildings in hot summer and cold winter zone, 
the results of choosing the exterior wall insulation configurations and balancing the thermal performance of exterior walls and partitions are significantly different with northern area where continuous and whole-space heating method was adopt. Systematic experimental research is necessary as most of previous studies still stay in the theoretical simulation phase. To achieve this purpose, a series of experiments were conducted in Shaoxing, a typical city in the hot summer and cold winter zone, to figure out the energy saving performance of different wall insulation configurations. A typical intermittent heating schedule was executed.

\section{Methodology}

If we can figure out the heat loss way in buildings with the intermittent and compartmental $\mathrm{A} / \mathrm{C}$ served in winter, the different energy saving performance for different wall insulation configurations could be explained. Take one single room as the analyzing unit, the heat gain ways are as follows [10]: from the $\mathrm{A} / \mathrm{C}$ system or heater $\left(\mathrm{Q}_{1}\right)$, from the solar radiation $\left(\mathrm{Q}_{2}\right)$, released from human body and equipment such as lamps $\left(\mathrm{Q}_{3}\right)$. The heat loss ways are mainly as follows: thermal storage for building envelope $\left(\mathrm{Q}_{4}\right)$, transfer to outer space through building envelope $\left(\mathrm{Q}_{5}\right)$, absorbed by the indoor air $\left(\mathrm{Q}_{6}\right)$, through the infiltration $\left(\mathrm{Q}_{7}\right)$.

The heat balance equation is:

$$
\mathrm{Q}_{1}+\mathrm{Q}_{2}+\mathrm{Q}_{3}=\mathrm{Q}_{4}+\mathrm{Q}_{5}+\mathrm{Q}_{6}+\mathrm{Q}_{7}
$$

The Q3 can be left out in the experiment. So will be the Q2 if heating at night, then (1) will be:

$$
\mathrm{Q}_{1}=\mathrm{Q}_{4}+\mathrm{Q}_{5}+\mathrm{Q}_{6}+\mathrm{Q}_{7}
$$

As building envelope includes wall, ceiling, floor, window and door, we have:

$$
\mathrm{Q}_{4}=\mathrm{Q}_{\mathrm{q}}+\mathrm{Q}_{\mathrm{f}}+\mathrm{Q}_{\mathrm{c}}+\mathrm{Q}_{\mathrm{w}}+\mathrm{Q}_{\mathrm{d}}
$$

The $\mathrm{Q}_{1}, \mathrm{Q}_{4}, \mathrm{Q}_{5}, \mathrm{Q}_{6}$ and $\mathrm{Q}_{7}$ can be given by:

$$
\mathrm{Q}_{1}=W \times \mathrm{COP}
$$

where $W$ is the $\mathrm{A} / \mathrm{C}$ load $(\mathrm{kWh})$ and COP stands for the $\mathrm{A} / \mathrm{C}$ system heating energy efficiency ratio (the value in this experiment was 2.6).

$$
Q_{4}+Q_{5}=\sum_{\mathrm{m}=1}^{60 \mathrm{n}} A \mathrm{q}_{\mathrm{m}} * 60
$$

where $n$ is the heating hours (h), $A$ is the area of building envelope $\left(\mathrm{m}^{2}\right), q_{m}$ stands for the average heat flow density of the inner surface of wall at the $\mathrm{m}$ minute which can be calculated by:

$$
q_{m}=h_{\text {in }}\left(T_{1}-T_{\text {in }}\right)
$$

where $T_{1}$ is the average temperature of the inner surface of wall at the m minute, $T_{\text {in }}$ is the average temperature of indoor air at the m minute and $h_{\text {in }}$ stands for the heat transfer coefficient of interior surface (the value in this experiment was $8.7[13])$.

$$
Q_{4}=\mathrm{c} \rho V\left(\overline{T_{n}}-\overline{T_{0}}\right)
$$

where $\mathrm{c}$ is the specific heat of building envelope $\left(\mathrm{J} \cdot \mathrm{kg}^{-1} \cdot \mathrm{K}^{-1}\right)$, $\rho$ is the density of building envelope $\left(\mathrm{kg} \cdot \mathrm{m}^{-3}\right), V$ is the volume of building envelope $\left(\mathrm{m}^{3}\right), \bar{T}_{n}$ is the average temperature of building envelope after completing the heat storage progress $(\mathrm{K}), \bar{T}_{0}$ is the initial average temperature of building envelope.

$$
\begin{aligned}
& Q_{6}=\mathrm{c}_{\text {air }} \rho_{\text {air }} V_{\text {air }}\left(\overline{T_{i n}}-T_{\mathrm{in} 0}\right) \\
& Q_{7}=\mathrm{nEc}_{\text {air }} \rho_{\text {air }} V_{\text {air }}\left(\overline{T_{i n}}-\overline{T_{\text {out }}}\right)
\end{aligned}
$$

where $\overline{T_{i n}}$ is the average temperature of indoor air during the heating time $(\mathrm{K}), T_{\mathrm{in} 0}$ is the initial temperature of indoor air (K), $\overline{T_{\text {out }}}$ is the temperature of outdoor air $(\mathrm{K}), \mathrm{c}_{a i r}$ stands for the specific heat of air (take $1004 \mathrm{~J} \cdot \mathrm{kg}^{-1} \cdot \mathrm{K}^{-1}$ ), $\rho_{\text {air }}$ is the density of air (take $1.29 \mathrm{~kg} \cdot \mathrm{m}^{-3}$ ). E stands for the actual room ventilation rate $\left(\mathrm{h}^{-1}\right)$, which can be measured by the tracer gas method $\left(\mathrm{CO}_{2}\right.$ was chosen in this experiment)[14]. It can be calculated by:

$$
E=2.30257 \cdot \lg \frac{\mathrm{c}_{1}-\mathrm{c}_{\mathrm{a}}}{\mathrm{c}_{2}-\mathrm{c}_{\mathrm{a}}}
$$

where $c_{1}$ is the initial content of $\mathrm{CO}_{2}$ in the room (\%), $\mathrm{c}_{2}$ is the content of $\mathrm{CO}_{2}$ in the room after 1 hour $(\%), \mathrm{c}_{\mathrm{a}}$ is the content of $\mathrm{CO}_{2}$ in the outdoor air (take $0.04 \%$ ), 2.30257 is the reduction coefficient between common logarithm (lg) and natural logarithm (ln).

\section{EXPERIMENT APPROACH}

\section{A. The Experimental House and A/C Operation Scheme}

The hot summer and cold winter zone locates at the center of China. The average temperature of the hottest and coldest month are $25-30{ }^{\circ} \mathrm{C}$ and $2-7{ }^{\circ} \mathrm{C}$ respectively, which are about $2{ }^{\circ} \mathrm{C}$ higher and $8{ }^{\circ} \mathrm{C}$ lower than the same latitude in the world [15].

The experimental house was a five-story residential building located in Shaoxing, Zhejiang province. Three adjacent rooms $(2 \mathrm{~F}, 3 \mathrm{~F}, 4 \mathrm{~F})$ at the southeast corner of the house have been executed a typical intermittent heating schedule at the same time. Among the three rooms, exterior walls of the room at the second floor were external insulated (EXT). Those at the fourth floor were internal insulated (INT), while those at the third floor were with no insulation (NI). Fig. 1 shows the typical floor plan of the house in which the shaded area indicates the experiment room (room $\mathrm{A}$ and room B) of each floor. The exterior walls of room A are south and east walls while the interior walls are north and west walls. The window wall ratio is 0.33 . Thermal parameters of the building envelope are shown in Table I.

All the rooms were used as bedrooms and the time of daily heating was from 22:00 to 6:00 in the next day. Two operation schemes were considered and each operation phase lasted two weeks to cover different weather conditions as much as possible. In phase 1, only room A in each floor was served by a wall-type separate air-conditioner with a set temperature of $26^{\circ} \mathrm{C}$. In phase 2 , both room A and room B in 
each floor were $\mathrm{A} / \mathrm{C}$ served, which means that there was room heating next to the west wall of room $\mathrm{A}$. When $\mathrm{A} / \mathrm{C}$ was off, windows were opened and the indoor air temperature was able to float to its balanced condition with the outdoor environment.

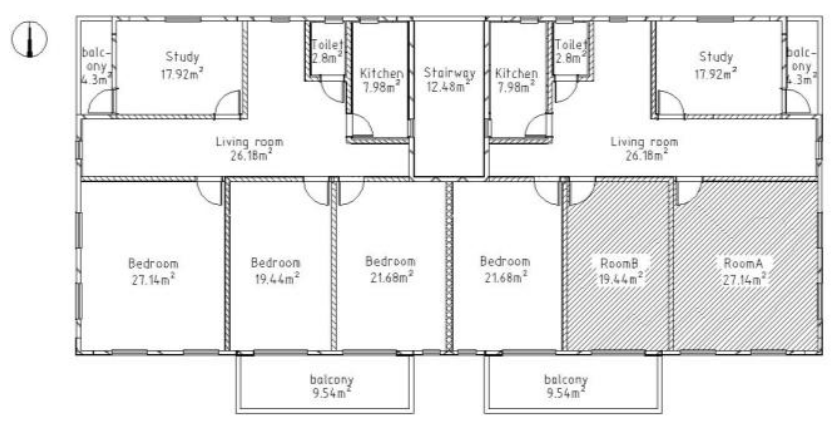

Fig. 1.The typical floor plan of the house.

TABLE I: THERMAL PARAMETERS OF THE BUILDING ENVELOPE FOR EXPERIMENT

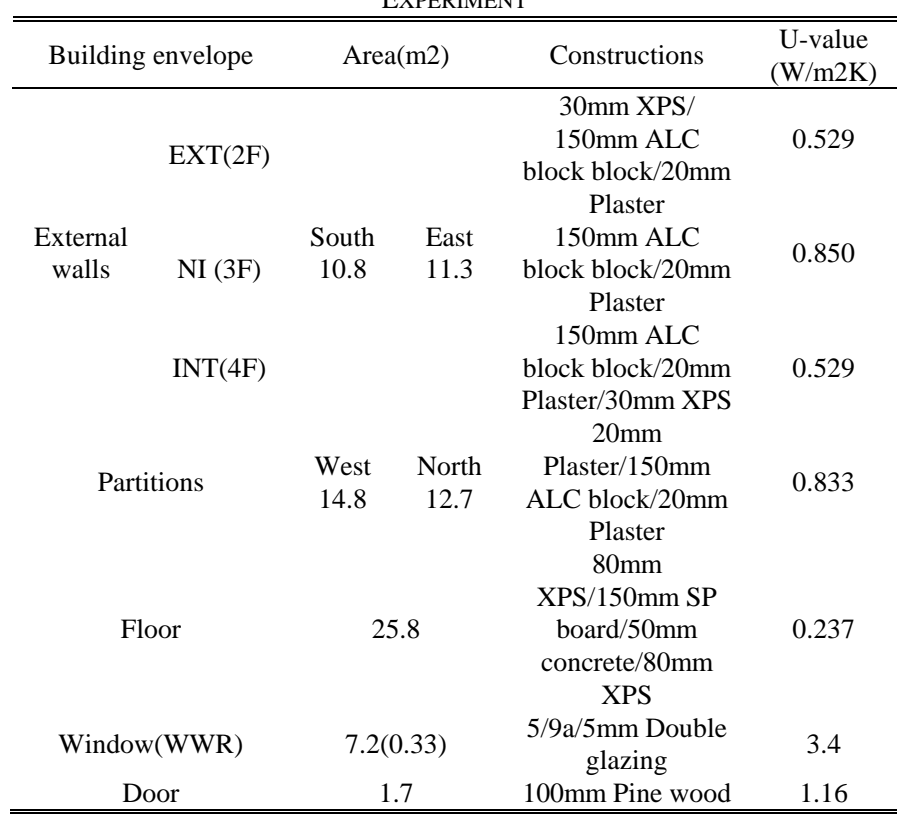

\section{B. Measuring Instruments}

The indoor and outdoor air temperature, the inner and outer surface temperature of building envelope, the central point temperature of walls and the interface temperature between wall and insulating layer were recorded in the Agilent 34970A data acquisition unit at an interval of 1 minute. Fig.2 shows the number and position of the temperature measuring points in walls. Platinum resistance temperature sensor with tolerance of $0.3{ }^{\circ} \mathrm{C}$ was used for temperature measurements. The total energy consumption of the air-conditioner was recorded by S350 type electric meters. The room ventilation rate during heating are measured according to formula (6) and the dissipation progress of $\mathrm{CO}_{2}$ are recorded by the EZY-1 type $\mathrm{CO}_{2}$ recording meter.

\section{RESUlTS AND DisCUSSION}

\section{A. Energy Saving Effect of Wall Insulation}

According to formula (2)-(10), the daily total heat loss and its distribution in room $\mathrm{A}$ with different wall insulation configurations in the two phases were calculated and shown in Fig.3. The broken line indicates the average daily heating amount offered by A/C according to formula (4), in which the total energy consumption of the air-conditioner was recorded by S350 type electric meters. The small difference between recorded value from the electric meters and the integrated value (daily total heat loss) demonstrates the accuracy of the calculation method. The simplified measuring method of using one point temperature to represent the average wall temperature may be the main reason for the deviation.
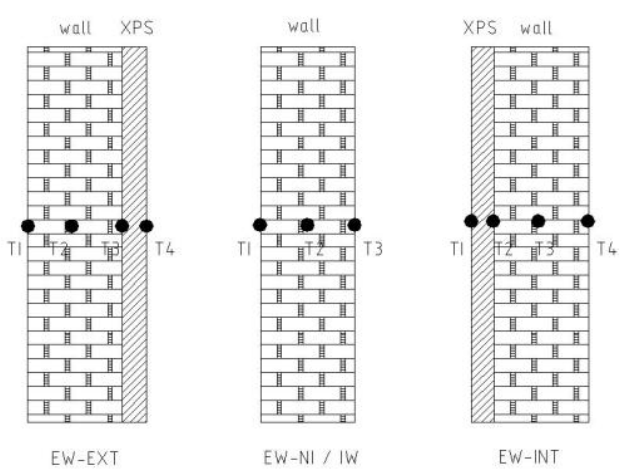

Fig. 2. Position of the temperature measuring points in wall. The left is indoor side and the black point represents the type $\mathrm{T}$ thermocouple sensors.

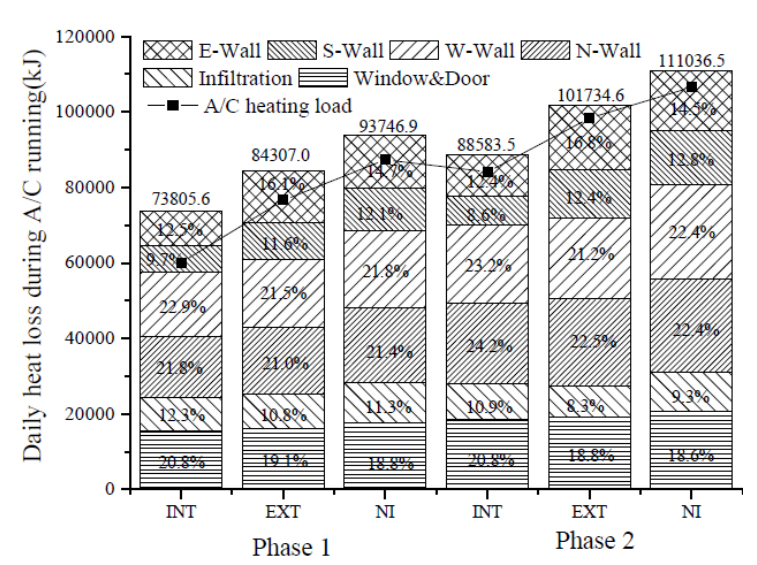

Fig. 3. Recorded A/C heating load and the daily average heat loss components for each insulation configuration in two phases.

As is shown in Fig. 3, infiltration accounted for the least amount of total heat loss $(8.3 \% \sim 12.3 \%)$ under the condition of intermittent heating. Most part of heat provided by $\mathrm{A} / \mathrm{C}$ was consumed for the heat storage of building envelope and the heat transfer through building envelope. The percentage of daily heat loss through the exterior walls (the east and south walls) with different insulation configurations changed the most $(21.0 \% \sim 29.2 \%)$ and it was the main reason for the difference in total heating load. Comparing with NI room, INT reduced heating load by $21.3 \%$ in phase 1 and $20.2 \%$ in phase 2, EXT reduced heating load by $10.1 \%$ in phase 1 and $8.4 \%$ in phase 2 .

The daily heating loads in phase 2 were larger than phase 1 . It was probably caused by the difference of weather in the two phases. Room A and room B shared one interior wall (west wall for room A). The percentage of daily heat loss through the west wall is only a little larger than the north wall in phase 1 . The situation has reversed in phase 2 but changed 
not too much. Whether the next room (room B) heating or not has little effect on reducing the percentage of heat loss through the west wall and the daily total heating load of room A. The percentage of daily heat loss through partitions (the west and north walls) was the most $(42.42 \% \sim 47.34 \%)$. With the intermittent and compartmental heating method, the total heating load and the heat loss through partitions will significantly decrease if the partitions of residential buildings were internal insulated.

\section{B. The Influence of the Intermittent Heating Method}

To figure out the reason of different energy saving performance for different wall insulation configurations, the temperature of measuring points in the south wall of room A at each floor on one typical day in phase 1 are shown in Fig. 4 (a) (b) (c). $\mathrm{T}_{\text {in }}$ indicates the indoor air temperature and $\mathrm{T}_{\text {out }}$ indicates the outdoor air temperature. $\mathrm{T}_{1}-\mathrm{T}_{4}$ indicates the temperature of measuring points imbedded in walls, of which the positions are shown in Fig. 2. It is shown in Fig.4 that the temperature of the internal surface of wall fluctuated with the indoor air. The temperature gradually dropped down from inside to outside during heating period and the direction of heat flow was simply from inside to outside. In Fig. 4 (a) (b) (c), the shaded part indicates the temperature difference between the inner surface of wall and the indoor air. The bigger the area of the shaded part during heating time was, the larger the heat loss in walls, according to formula (5) (6).

It can be calculated with formula (7) (8) (9) that: in the whole heating period, the heat storage of walls with different insulation configurations were different and the average value was $59862.0 \mathrm{~kJ}$. The heat storage of indoor air in different floors was similar and the average value was $2060.5 \mathrm{~kJ}$. The wall heat storage was 29 times of the indoor air. The process of heat accumulation in building envelope would repeat with the intermittent heating method and it became the main factor of influencing the energy saving performance of different wall insulation configurations.

Taking the average temperature of wall (regardless of the insulation layer) in Fig. 4 (a) (b) (c) as the indicator, the wall heat storage with INT method was the lowest compared with the EXT and NI method. The process of heat accumulation in walls has mainly completed when the air condition stopped heating for the first time, because the rising speed of wall temperature markedly slowed down after the continuous heating period. The duration of this period was $130 \mathrm{~min}$ for NI room, 105 min for EXT room (reduced by nearly 20\%) and $55 \mathrm{~min}$ for INT room (reduced by nearly 60\%). Therefore, heat storage in building envelope is the main influence on the energy saving performance of different wall insulation configurations under the intermittent heating condition. Generally speaking, the energy saving effect was greatly effect by A/C operation mode. Yan [16] investigated a residential building in Shanghai and found out that the energy saving effect of external insulation is remarkable under the continuous heating method, and in the actual way of intermittent energy next few energy. Ruan [17] established a two-dimensional heat transfer model and results showed that there existed anti-insulation behavior for external insulation with intermittent energy consuming mode in hot summer and cold winter region. Reference [18] also showed that the tolerate temperature greatly affected the wall insulation effect.

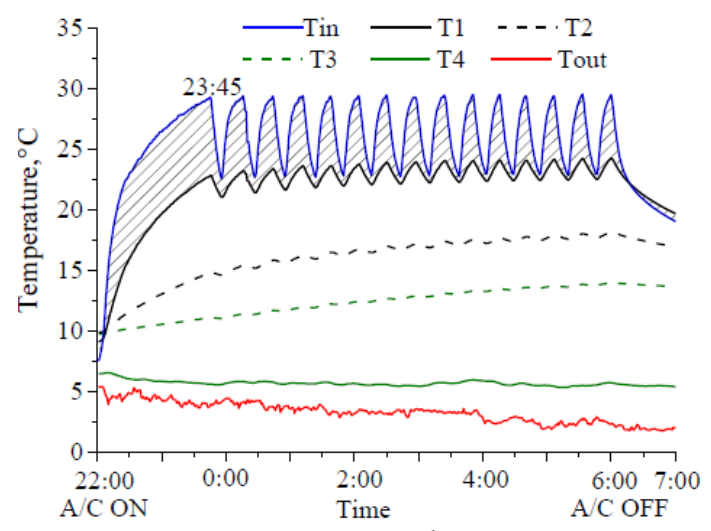

(a) EXT room ( $2^{\text {nd }}$ floor $)$

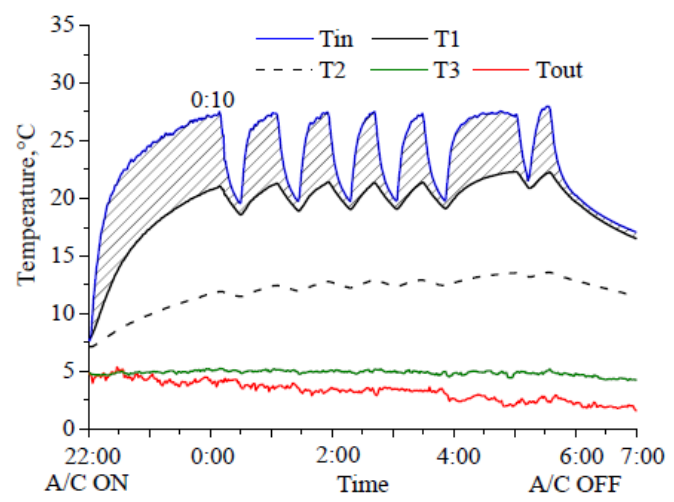

(b) NI room ( $3^{\text {rd }}$ floor)

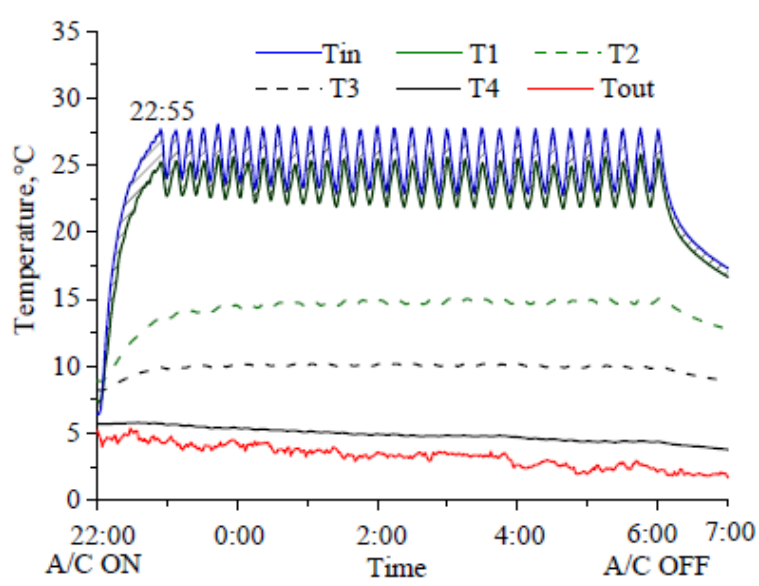

(c) INT room $\left(4^{\text {th }}\right.$ floor)

Fig. 4. Temperature of measuring points in the south wall of room A of each floor on one typical day in phase 1 ; (a) EXT room ( $2^{\text {nd }}$ floor $)$, (b) NI room ( $3^{\text {rd }}$ floor) and (c) INT room ( $4^{\text {th }}$ floor).

\section{The Influence of the Compartmental Heating Method}

As referred in Fig. 3, whether the adjacent room (room B) heating or not have little effect on reducing the percentage of heat loss in the west wall and the daily heating load of room A. This conclusion can be explained by Fig. 5 (a) (b).

Fig. 5 (a) shows the temperature of measuring points in the west wall of NI room on the same day in phase 1 with Fig. 4 (b). During the heating period, the heat flow in the west wall was in one direction as the temperature gradually dropped down from room A to room B. At the end of heating time, the process of heat accumulation for the west wall generally completed and the heat transfer became the mainly approach 
for heat loss. Fig. 5 (b) shows the temperature of measuring points in the west wall of NI room on one typical day in phase 2. Due to the adjacent room was heating at the same time, the center temperature of the west wall was lower than both sides and the heat flow was from two sides of wall to the center. At the end of heating time, the center temperature of the west wall was still the lowest. It indicates that the west wall was unable to complete the process of heat accumulation in the typical intermittent heating period ( $8 \mathrm{~h})$ even if the adjacent room was heating at the same time. In reference [12], the heat loss through partitions accounts for about $70 \%$ of the total energy consumption in extreme operation case. Reference [18]also showed the heat loss through partitions is enormous and unit design is needed.

As the percentage of daily heat loss of partitions (the west and north wall) was the most $(42.42 \% \sim 47.34 \%)$ with the intermittent and compartmental heating method, the total heating load and the heat loss of partitions would significantly decrease if the partitions were internal insulated.

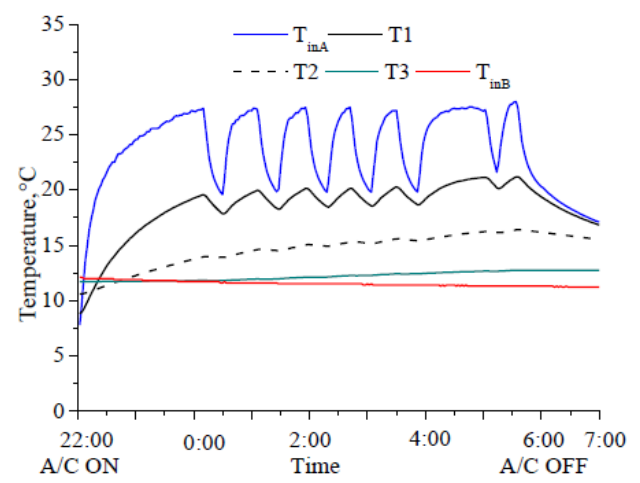

(a) phase

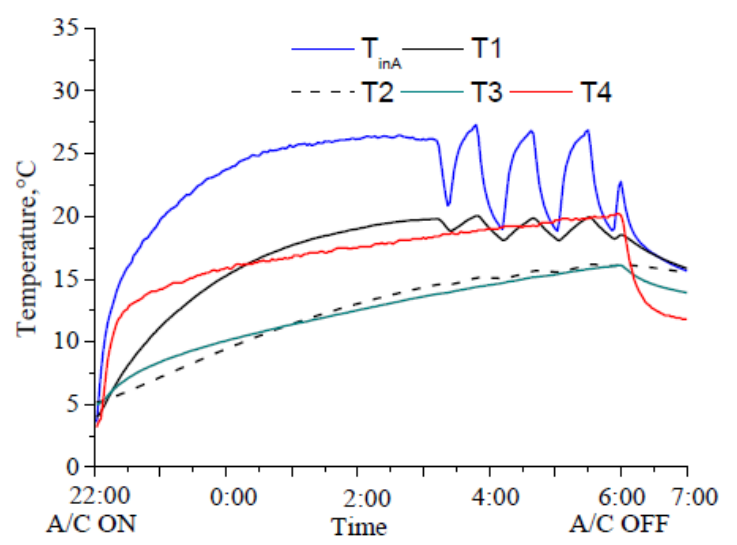

(b) phase 2

Fig. 5. Temperature of measuring points in the west wall of room A in $3 \mathrm{~F}$ (NI) on one typical day in (a) phase 1 and (b) phase 2.

\section{CONCLUSION}

Based on the intermittent and compartmental heating method, a series of experiments were conducted in a typical city in the hot summer and cold winter zone to figure out the energy saving performance of different wall insulation configurations. The results showed as follows:

With the intermittent heating method, the wall heat storage was 29 times of the indoor air heat storage and it became the main influence on the wall insulation effect. Internal insulation would greatly reduce the heat storage in wall and decrease more heating load compare with external insulation.

With the intermittent and compartmental heating method, the percentage of daily heat loss in partitions was the most. Whether the adjacent room heating or not have little effect on reducing the percentage of heat loss in partitions and the total heating load. Interior wall was unable to complete the process of heat accumulation in the typical intermittent heating period ( $8 \mathrm{~h}$ ) even if the adjacent room was heating at the same time. The total heating load and the heat loss in partitions will significantly decrease if the partitions were internal insulated.

Limited by time, it was unable to cover the whole heating period. Besides, heat from human body and equipment like lamp was left out as these were not the main factors that influence the conclusion.

\section{REFERENCES}

[1] Y. Wang, Z. Huang, and L. Heng, "Cost- effectiveness assessment of insulated exterior walls of residential buildings in cold climate," International Journal of Project Management; vol. 25, no. 2, pp 143-149. Feb. 2007.

[2] N. Ghrab-Morcos, "CHEOPS: A simplified tool for thermal assessment of Mediterranean residential buildings in hot and cold seasons," Energy and Buildings, vol. 37, no . 6, pp. 651-662, June 2005.

[3] M. S. Mohsen and B. A. Akash, "Some prospects of energy savings in buildings," Energy Conversion and Management, vol. 42, no. 11, pp 1307-1315, July 2001

[4] S. A. Mohammad, "Performance characteristics and practical applications of common building thermal insulation materials," Building and Environment, vol. 40, no. 3, pp 353-366, March 2005.

[5] N. Daouas, Z. Hassen, and H. B. Aissia, "Analytical periodic solution for the study of thermal performance and optimum insulation thickness of building walls in Tunisia," Applied Thermal Engineering, vol. 30, pp 319-326, March 2010.

[6] M. Ozel, "Thermal performance and optimum insulation thickness of building walls with different structure materials," Applied Thermal Engineering, vol. 31, pp 3854-3863, December 2011.

[7] X. Qian and Y. Zhu, "Basic research direction and problems existed in building energy saving in hot summer and cold winter climate zones," Construction Technology, vol. 358, no. 41, pp. 27-29, Feb. 2012.

[8] E. Kossecka and J. Kosny, "Influence of insulation configuration on heating and cooling loads in a continuously used building," Energy and Buildings, vol. 34, no. 4, pp. 321-331, May 2002.

[9] C. Balocco, G. Grazzini, and A. Cavalera, "Transient analysis of an external building cladding," Energy and Buildings, vol. 40, no. 7, pp. 1273-1277, 2008.

[10] J. Li, "Energy saving effect of thermal insulation walls for residential buildings in hot summer and cold winter zone," Master Thesis, Dept. building materials, Zhejiang Univ, Hangzhou, China, 2013.

[11] D. Pan, M. Chan, S. Deng, and Z. Lin, "The effects of external wall insulation thickness on annual cooling and heating energy uses under different climates," Applied Energy, vol. 97, pp. 313-318, September 2012.

[12] X. Qian and Y. Zhu, "Basic research on the building energy consumption base on the intermittent and loculose energy use characteristics," Civil Engineering Journal, vol. 43, pp. 392-399, 2010.

[13] Thermal Design Code for Civil Building, GB 50176-93.

[14] Method for Measurement of Infiltration Rates of Indoor Air in Public Places, GB/T18204.19-2000.

[15] Design Standard for Energy Efficiency of Residential Buildings in Hot Summer and Cold Winter Zone, JGJ 134-2010.

[16] S. Y. Guo, Y. Da, and C. Yin, "Analysis on the influence of occupant behavior patterns to building envelope's performance space heating in residential buildings in Shanghai," in Porc. International Building Performance Simulation Association. Proceedings of 2nd Asia Conference of International Building Performance Simulation Association, 2014, pp. 610-616.

[17] R. Fang, X. Q. Qian, Z. Yao et al., "Internal and external wall insulation effect on building energy efficiency with compartmental and intermittent energy consuming method," Journal of Zhejiang University (Engineering Science), vol. 50, no. 1, pp. 1-7, 2015.

[18] Y. W. Jian, M. Gao, and P. Ze, "Study on the ON Schedule of Split Air Conditioners in Apartments," Building Science, vol. 31, no. 10, pp. 222-27, 2015. 
[19] R. Fang, X. Q. Qian, Z. Yao et al., "Research on energy efficiency design for residential building envelope under the actual energy consuming method in hot summer and cold winter zone," Building Science, vol. 31, no. 10, pp. 112-116, 2015.

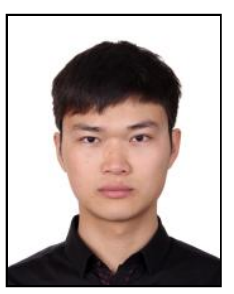

Ruan Fang was born in Hangzhou, in 1990. He received his $\mathrm{PhD}$ of structural engineering, research center of green building and low-carbon city at the Department of Civil Engineering, University of Zhejiang, Hangzhou, P. R. China in 2012.

He received his bachelor of civil engineering at the Department of Civil Engineering, University of Nanchang, Nanchang, P. R. China during 2008-2012.

He has published paper title "Wall insulation effect on building energy efficiency with the intermittent and compartmental energy consuming method, " in Chinese in Ei. He is a first author.

He has published paper title "Analysis on the operation mode relating to residential building cooling load in hot summer and cold winter zone," in ISTP. He is a first author.

He has published paper title "Research on energy efficiency design for residential building envelope under the actual energy consuming method in hot summer and cold winter area," in Chinese, in GCJC. He is a first author 